\title{
AMBIENTE E CIDADANIA: EDUCAÇÃO AMBIENTAL NAS ESCOLAS
}

\section{ENVIRONMENT AND CITIZENSHIP: ENVIRONMENTAL EDUCATION IN SCHOOLS}

\author{
Maristela Gonçalves Giassi ${ }^{1}$ \\ Júlia Formentin Dajori ${ }^{2}$ \\ Anice Cardoso Machado ${ }^{3}$ \\ Miriam Conceição Martins ${ }^{4}$
}

\begin{abstract}
RESUMO
Este artigo tem por objetivo relatar o desenvolvimento de um projeto de Extensão focado na Educação Ambiental nas escolas. As atividades envolviam reflexões pautadas na compreensão das interações entre os sistemas que constituem o nosso planeta - físicos químicos, biológicos e sociais. Nele foram utilizados recursos diversos da UNESC, como a Biblioteca, o Centro de Educação Ambiental - CEA/UNESC, o Laboratório de Prática de Ensino de Ciências, o Horto, o Museu de Zoologia, entre outros, visando à construção de uma consciência ambiental e mudança de hábitos e atitudes mais favoráveis aos cuidados com o ambiente. Procurou-se desenvolver atividades educativas que estimulavam aos estudantes e professores diagnosticar e atuar sobre os problemas ambientais no seu ambiente de vida. Entre as atividades destacamos: Palestras, oficinas, trilhas, jogos educativos, visitas ao horto, Laboratórios, simulações, entre outros. Os resultados indicam que as atividades contribuíram com alunos, professores e escolas, pois nos feedback dado pelos professores e pelas escolas, seus alunos já demonstram maior cuidado com o ambiente escolar e com os colegas. Além disso, os professores relatavam a alegria dos alunos em participarem dessas atividades em ambientes diferenciados proporcionando um aprendizado mais significativo e também o seu próprio aprendizado sobre o tema.

Palavras-chave: Educação Ambiental; Escolas; Meio Ambiente.
\end{abstract}

\begin{abstract}
This article aims to report the development of an extension project focused on environmental education in schools. The activities involved guided reflections to understand interactions between the systems that make up our planet - chemical physical, biological and social. It was used several features of UNESC, as the Library, the Environmental Education Center - CEA / UNESC, the Science Teaching Practice Laboratory, the Garden, the Museum of Zoology, among others, aimed at building environmental awareness and changing habits and more favorable attitudes towards care for the environment. We sought to develop educational

\footnotetext{
${ }^{1}$ Professora do Curso de Ciências Biológicas da UNESC/ UNAHCE/ Coordenadora do Projeto. E-mail: mgi@unesc.net.

${ }^{2}$ Acadêmica do Curso de Engenharia Ambiental UNESC/UNACET. E-mail: juliadajori@gmail.com.

${ }^{3}$ Acadêmica do Curso de Ciências Biológicas da UNESC/UNAHCE. E-mail: anicemachado@ @otmail.com.

${ }^{4}$ Professora do Curso de Ciências Biológicas da UNESC / UNAHCE. E-mail: mcm@ unesc.net.
} 
activities that encouraged students and teachers to diagnose and act on environmental problems in their living environment. Among the activities include: Lectures, workshops, trails, educational games, visits to the garden, laboratories, simulations, among others. The results indicate that the activities have contributed to students, teachers and schools, because the feedback given by teachers and schools, their students already show great care with the school environment and with colleagues. In addition, teachers reported the joy of students participate in these activities in different environments providing a more meaningful learning and also their own learning on the subject.

Keywords: Environmental Education; Schools; Environment.

\section{INTRODUÇÃO}

Ao observar a natureza é possível perceber as relações existentes entre os seres vivos. A percepção sobre o que acontece ao obsevar o entorno traz consigo um borbulhar de ideias, hipóteses e curiosidades. Ela fornece subsídios necessários para se obter o autoconhecimento, adquirindo e resgatando valores e habilidades e despertando a sensibilidade do indivíduo (SILVA; ROZA-GOMES; OLIVEIRA, 2010).

A Lei n. 9.795, de 27 de abril de 1999, que institui a Política Nacional de Educação Ambiental, relata em seu Art. $1^{\circ}$, que se entende por Educação Ambiental os processos em que indivíduos e coletividade constroem valores sociais, conhecimentos, habilidades, atitudes e competências voltadas à conservação do meio ambiente, o que é essencial à sadia qualidade de vida e sua sustentabilidade (BRASIL, 2005).

Esta necessidade manifesta-se devido às grandes alterações ocorridas ao longo da História Humana e suas relações com os recursos naturais para a sobrevivência da espécie. Conforme Gutierrez e Prado (1999) a crise atual não é uma crise pertinente a apenas um indivíduo ou uma sociedade, mas, sim, uma crise de dimensões planetárias. De acordo com os autores, este fato requer uma profunda mudança na forma de perceber e compreender o mundo, nas relações e nas inter-relações entre os diversos organismos que habitam o planeta. Exige uma revisão de valores, hábitos, atitudes e estilos de vida, na tentativa de criar um meio ambiente físico, mental e espiritual mais saudável e que cause menos problemas às gerações vindouras.

A evolução da relação homem/natureza e dos paradigmas dominantes resultou em uma crise de percepção da realidade, como sugere Capra (1996). Segundo o autor, os diversos problemas enfrentados na atualidade não podem ser entendidos isoladamente, uma vez que são interligados e interdependentes. Por esse motivo, devem ser compreendidas como as diferentes facetas de uma mesma crise, derivada de uma visão ultrapassada de mundo e inadequada à realidade. 
Conforme indaga Branco (2003), como tratar bem o ambiente natural quando o próprio homem não trata bem a si mesmo? A crise ambiental se origina pela própria crise da existência humana, o que leva Capra (1996) a defender uma mudança radical de paradigma; nossos valores, pensamentos e percepções em relação ao mundo. Este paradigma, denominado de holístico ou visão ecológica, concebe o mundo de forma interligada e interdependente - os mesmos princípios praticados pelo homem no início de sua história. $\mathrm{O}$ proposto pensamento ecológico necessariamente nos remete ao pensamento complexo, que, segundo Pena-Vega (2003), a natureza passa a ser percebida como uma totalidade complexa, em vez de desordenada e passiva. Ao mesmo tempo, o homem não seria uma entidade fechada e excluída dessa totalidade, mas um sistema aberto autônomo-dependente no seio de uma complexidade do qual faz parte.

Essa complexidade, segundo Branco (2003), pode ser relacionada com as questões ambientais como um problema que passa pela história cultural do ocidente, capitalista, voltado para a tecnologia, que tem por meta a produção em massa e a padronização e que dá a ilusão de um crescimento ilimitado, privilegiando alguns segmentos da sociedade, em detrimentos de outros.

A partir desse panorama de crise e propostas de complexificação e holismo surge a Educação Ambiental (EA). Comprometida com a conscientização e participação da sociedade nos problemas socioambientais, propondo um olhar interdisciplinar para os conhecimentos nela tratados.

Segundo Morin (2006, p. 42), “como nossa educação nos ensinou a separar, compartimentar, isolar e, não, a unir os conhecimentos, o conjunto deles constitui um quebracabeças ininteligível". O autor destaca que quando se observa a história da Educação ou da Pedagogia percebe-se que a maioria das pessoas foram educadas da mesma forma, de um modo rígido, fragmentado e autoritário, sem que compreendam as ligações existentes entre os conhecimentos científicos e a sua própria cultura

A forma disciplinar que impera nas escolas gera conhecimentos limitados. Segundo Lück (1994) esta visão pautada na fragmentação do ensino sustenta a visão e a produção de conhecimentos limitados e restritos, estabelecendo limites que não se deve ultrapassar. Essas fronteiras estabelecidas pelas disciplinas não fazem mais sentido para a escola atual, onde o contexto e as realidades não se separam mais da vida escolar, e também onde alunos curiosos e críticos estão questionando os conteúdos e sua utilidade no dia a dia. Lück (1994, p. 39) afirma que: 
[...] O ensino deixa de formar cidadãos capazes de participar do processo de elaboração de novas ideias e conceitos, tão fundamental para o exercício da cidadania crítica e participação na sociedade moderna, onde tanto se valoriza o conhecimento.

Neste sentido Freire (2005) nos lembra da importância de se tratar nas escolas das "contradições" em que vivem muitos de seus alunos, ou seja, trata-se na escola, por exemplo, de qualidade de vida relacionada à aquisição de objetos de valores e qual a realidade vivida por nossos estudantes? Como vivem suas famílias? O ato de educar ambientalmente implica em mudanças de visão de mundo e no modo como nos relacionamos com ele. A escola é o lugar onde, de maneira mais sistemática e orientada, aprendemos a ler o mundo e a interagir com ele, sendo este um dos motivos que nos leva a insistir em educação nas escolas.

\section{Desafios da educação ambiental}

Controlar o impulso consumista atual na sociedade é um desafio existente para solucionar os problemas ambientais. Alguns estudiosos como Frei Betto (2005) e Pereira (2007) observam que em muitos casos os filhos herdam os impulsos consumistas dos pais e através do ambiente em que convivem além da casa. Esse processo começa no controle dos gastos de uma criança em casa. Os autores apontam exemplos como: fraldas descartáveis, brinquedos de plástico, televisão ligada por horas, gasto de água, entre outros costumes, que podem desperdiçar recursos naturais e gerar grande quantidade de resíduos sólidos. Essa carga consumida pelos pais reflete o possível comportamento futuro da criança, que por consequência reproduzirá os hábitos de consumo dos pais; ao professor caberá o desafio de conscientizar e refletir sobre seus impactos gerados no ambiente, embora esse papel seja responsabilidade de todos os atores da sociedade, não somente da escola.

As inovações tecnológicas, principalmente a partir do século XVIII, proporcionam maior velocidade ao processo de transformação da matéria-prima. Dessa forma, devido ao crescimento econômico gerado pela Revolução Industrial, a humanidade desenvolveu hábitos sociais que geram uma série de problemas ambientais, surgindo a necessidade do estabelecimento da educação ambiental nas redes escolares (MARTINS; FROTA, 2013).

Ao lecionar, o professor precisa aliar os conhecimentos exigidos nos currículos escolares com a Educação Ambiental. Esta atitude, embora direcionada legalmente, deveria fazer parte da rotina do professor em sala de aula, já que o aluno permanece com ele por várias horas no dia. Desse modo os alunos podem fazer maiores relações entre as relações constituinte do universo, ou seja, físicos, químicos, biológicos e sociais, orientando, assim, processos interdisciplinares e ampliando a forma de percepção de mundo de todos. 
De acordo com a PC/SC (1998) a conceituação de meio ambiente envolve uma série de interrogações que nem sempre estão respondidas para cada indivíduo, dificultando um posicionamento definitivo. Por exemplo, para muitos a relação homem/natureza pode ser compreendida de uma forma dicotômica, enquanto sabemos que a natureza e a sociedade não se excluem mutuamente. Nesse sentido, Moscovici (1987, p. 142) alerta que "somos parte da natureza e por razões não só, mas também biológicas, transformamos-la e isso faz parte do nosso processo histórico-cultural". Ou seja, o conceito de natureza nos leva aos recursos naturais que são usados, transformados histórica e culturalmente a partir de nossa intervenção social.

Neste cenário de fragmentações de recortes e especializações nos conhecimentos, a PC/SC (1998, p 48) nos lembra da dificuldade que temos em juntar estas partes para promover uma educação constituída de essências que permitam ver o todo que compõe o mundo que nos cerca.

Como se pode caracterizar uma educação que seja ambiental a tal ponto que o adjetivo possa ser omitido, uma vez que, na sua própria concepção (e execução), já explicite todas as exigências que ele pudesse carrear? É importante insistir: não se deseja, simplesmente, acrescentar mais uma disciplina ao programa, nem incluir determinados enfoques aos conteúdos da disciplina $\mathrm{X}$ ou $\mathrm{Y}$; propõe-se o desafio de uma educação tão completa, tão plena de significados, que contemple tantos aspectos importantes das relações homem/meio (na acepção tratada anteriormente), que o adjetivo "ambiental" se torne, efetivamente, desnecessário (SANTA CATARINA, 1998, p. 48).

A partir desse olhar percebe-se a importância do papel da educação na compreensão das questões ambientais, que usando ou não o adjetivo ambiental, proporcione nas escolas espaços de sensibilização e capacitação de alunos para uma tomada de consciência e ações concretas, aquisição de conhecimentos que permitam sua integração com a comunidade e a compreensão crítica da complexidade do mundo contemporâneo.

A questão da transversalidade, segundo Selbach et al. (2010), deve ser vista como uma modalidade de pensamento transversal e que percorre os capítulos da disciplina em qualquer item e em todos os anos letivos, confirmando o caráter interdisciplinar de seu conteúdo. Além disso, academicamente é capaz de articular o ensino, a pesquisa e a extensão, já que muitas das vezes, essas ações resultam de pesquisas que conduzem a processos educativos, possibilitando a indissociação necessária ao tripé que alicerça as Universidades brasileiras.

Assim, este artigo é resultado de um projeto de extensão, fruto de pesquisa realizada por membros do GPECEA - Grupo de Pesquisa em Ensino de Ciências e Educação Ambiental, que apontou a necessidade que os professores apresentaram nesta área do conhecimento e que foi conduzido de modo vinculado ao ensino. Teve como objetivo 
desenvolver ações de Educação Ambiental visando o desenvolvimento de atitudes e valores para a construção de um ambiente com maior qualidade de vida.

\section{DESENVOLVIMENTO}

Nas pesquisas que serviram de base para as ações desenvolvidas neste projeto, os professores responderam que nas escolas, muitas vezes lhes é solicitado que tratem de temas ambientais, que desenvolvam projetos de Educação Ambiental com seus alunos e que nem sempre sentem-se preparados para isso. Por esse motivo solicitam atividades que tragam subsídios que venham contribuir com suas aulas e seus projetos.

Assim, para iniciar as atividades foram realizados contatos com as escolas para conversar com equipe gestora, professoras e participantes do projeto. Após o contato procurou-se ouvir os professores e as suas necessidades para então se propor as ações e dar início ao processo educativo.

As atividades práticas, reflexivas e materiais didáticos necessários ao desenvolvimento das atividades são elaborados de acordo com a faixa etária dos envolvidos. A participação das escolas obedecem a duas modalidades: ou ia-se até as escolas desenvolver as atividades ou as escolas vinham com os alunos até a Universidade para participar delas.

Eram atendidos alunos nos três períodos de aulas: matutino, vespertino e noturno. No período noturno eram atendidos principalmente estudantes do Ensino Médio da Rede Pública de Ensino e do EJA - Educação para Jovens e Adultos. Os dois bolsistas que atendiam ao projeto se revezavam nos atendimentos dos três períodos, sendo que o maior volume de atendimentos era concentrado no período vespertino.

No atendimento às escolas a metodologia variava de acordo com a temática solicitada. Já nos atendimentos realizados na UNESC, normalmente era preparada uma recepção calorosa aos alunos, com alguma dinâmica alegre e descontraída envolvendo o tema ambiental, visando deixá-los mais dispostos a aprender e interagir com os colegas.

Dentre os temas mais solicitados para que se tratassem estavam: os resíduos sólidos e seu descarte correto; o lixo eletrônico e a contaminação do solo e da água; agrotóxicos e alimentação; solo e seus componentes; poluição do ar, da água e do solo. O tema "água" estava sempre presente quase como um motivador das reflexões. Em todas as atividades buscava-se realizar um processo num viés mais problematizador, direcionado para as questões mais próximas do contexto de vida dos participantes. 
Como parte reflexiva, ao final das atividades, era programado um "Papo Cabeça", momento dos alunos se expressarem com mais tranquilidade onde a equipe do projeto traz questionamentos e todo o grupo participa trazendo experiências diárias.

Após o "Papo Cabeça" propõe-se uma atividade prática que auxilie na fixação dos temas tratados anteriormente. Dependo da faixa etária dos alunos, há uma atividade diferenciada. Entre essas atividades práticas destacamos o plantio de uma muda de hortaliça, ou de flor, cultivada na horta do Centro de Educação Ambiental/UNESC. Todos podem leválas para casa e cultivá-las ou consumi-las sem preocupações, pois eram sempre naturais e sem aditivo de nenhuma espécie. Essa atividade propõe principalmente que o aluno prefira uma alimentação mais saudável e respeite os organismos vivos de forma geral.

Outra atividade proposta é chamada "EcoGame". Esta atividade é um jogo que propõe um teste aos conhecimentos dos alunos e professores, com 10 perguntas sobre resíduos sólidos especiais, lançadas aos alunos, que devem respondê-las corretamente. Alguns temas nelas abordados: resíduo hospitalar, nuclear e eletrônico. Esta atividade contribui para a interação entre os colegas na busca pelas respostas e descontração da turma, já que trabalham divididos em grupos. Além de trazer conhecimento e possibilitar boas relações entre todos os participantes.

Outra atividade proposta pela equipe do Projeto é a construção de um Papas-Pilhas, para descarte de pilhas e baterias já usadas. Este é deixado na escola para que todos tenham acesso e não venham a depositar esse material inadequadamente, contaminando o solo e possivelmente o lençol freático. A elaboração do Papas-Pilhas é feita com materiais recicláveis para incentivar práticas como a reutilização e reciclagem de materiais, focando no descarte correto após o uso e estabelecendo parcerias entre as escolas e instituições que darão o descarte correto, como a prefeitura ou centros de triagem de resíduos sólidos.

Os alunos sempre comentam que irão realizar essas práticas também em suas residências e outras instituições que frequentam.

\section{CONCLUSÃO}

As ações realizadas no projeto indicam as escolas como grandes beneficiadas com o processo, pois os alunos que participaram ativamente das aulas de Educação Ambiental mostraram-se mais preparados para respeitá-la, já que muitas dessas escolas são localizadas em regiões afetadas pela extração do carvão e em regiões periféricas da cidade. Muitas delas apresentam um ambiente com paredes riscadas, pátios e salas de aulas sujos, com papéis jogados no chão, carteiras riscadas, vidros quebrados, entre outros, e percebe-se que os 
estudantes tomam consciência de que o meio em que vivem é responsabilidade deles também. Os gestores e principalmente os professores observaram e relataram que os seus alunos desenvolveram algumas atitudes mais pacíficas e respeitosas com os colegas, com o pátio da escola e com a mobília da sala.

Além disso, sendo que as aulas do projeto são bem diversificadas em ambientes diferenciados e abertos, a vivência de experiências fora de sala de aula proporcionadas aos estudantes levaram os professores a afirmar que os conhecimentos adquiridos pelos alunos neste projeto certamente não serão esquecidas.

Por consequência a sociedade ganha, pois teremos cidadãos mais preparados para enfrentar os desafios da sociedade atual cujo maior dilema gira na solução dos problemas ambientais, pois envolvem aspectos econômicos, sociais, recursos naturais, éticos entre outros.

Assim, com este Projeto de Extensão envolvendo professores, alunos, escolas e até os familiares dos estudantes em decorrências do dia-a-dia, esperamos ter conseguido plantar a semente da sensibilização para a vida no seu todo. Entendemos que as escolas, em parceria com as Universidades e com as famílias, podem contribuir para espalhar alguma luz sobre as questões ambientais que hoje precisam ser encaradas de modo mais respeitoso para garantirmos ainda a qualidade de vida da população.

\section{REFERÊNCIAS}

BETTO, Frei. A publicidade infantil deve ser discutida em sala de aula. Portal Aprendiz. Rio de Janeiro, 22 de junho de 2012. Disponível em: $<$ http://portal.aprendiz.uol.com.br/2012/06/22/frei-betto-\%E2\%80\%9Ca-publicidadeinfantil-deveria-ser-discutida-em-sala-de-aula\%E2\%80\%9D/>. Acesso em: 16 mar. 2015.

BRANCO, S. M. Educação ambiental: metodologia e prática de ensino. Rio de Janeiro: Dunya, 2003.

BRASIL. Ministério do Meio Ambiente. Pronea. 3. ed. 2005.

CAPRA, Francisco. A teia da vida: uma nova compreensão científica dos sistemas vivos. São Paulo: Cultrix, 1996.

FREIRE, Paulo. Pedagogia do oprimido. 41 ed. Rio de Janeiro: Paz e Terra, 2005.

FREIRE, Paulo. Pedagogia do Oprimido. 43 ed. Rio Janeiro: Paz e Terra, 2005.

GUTIÉRREZ, F.; PRADO, C. Ecopedagogia e cidadania planetária. São Paulo: Cortez: Instituto Paulo Freire, 1999.

LÜCK, Heloisa. Pedagogia interdisciplinar: fundamentos teóricos-metodológicos. Rio de Janeiro: Vozes, 1994. 
MARTINS, Miriam da Conceição; FROTA, Paulo Rômulo de Oliveira. Educação Ambiental: A diversidade de um paradigma. Criciúma: UNESC, 2013.

MORIN, Edgar. Os sete saberes necessários à educação do futuro. 11 ed. São Paulo: Cortez; Brasília, DF: UNESCO, 2006.

MOSCOVICI, S. A Sociedade contra a natureza. Petrópolis, R. J.: Vozes, 1987.

PEREIRA, Laís Fontenelle. Que infância estamos construindo? Folha de São Paulo, São Paulo, 12 out. 2007.2 Disponível em: <http://www1.folha.uol.com.br/fsp/opiniao/fz1210200709.htm>. Acesso em: 16 mar. 2015.

PENA-VEGA, A. O despertar ecológico: Edgar Morin e a ecologia complexa. Rio de Janeiro: Garamond, 2003.

SANTA CATARINA. SECRETARIA DE ESTADO DA EDUCAÇÃO E DO DESPORTO. Proposta Curricular de Santa Catarina: Educação Infantil, Ensino Fundamental e Médio: Disciplinas curriculares. Florianópolis: COGEN, 1998.

SELBACH, Simone et al. Ciências e Didática. Petrópolis, RJ: Vozes, 2010.

SILVA, T.C.L.; ROZA-GOMES, M.F.; OLIVEIRA, A.D. Educação ambiental: um relato de atividades com embasamento científico. Revista Unoesc \& Ciência - ACBS, v. 1, n. 2, p. 125-134, jul./dez. 2010. 